transmission, for which technical policy is already co-ordinated by the Central Electricity Board.

For low-voltage distribution systems, a four-wire, three-phase, $400 / 230$ volt system is the national standard. Its extension throughout Great Britain is recommended as an urgent post-war national industrial plan. Data are given on which a scheme to secure standardization may be based. Complete standardization of all low-voltage distribution systems presents no technical difficulties and could be completed within five years. As the benefit of such voltage standardization mainly accrues to the entire community, it may be the subject of financial discussions with Government, and a detailed estimate has been made of its cost, which amounts to some $\mathfrak{\$ 1 7 . 5}$ millions, based on 1939 conditions and pricelevels.

A brief historical review of the development of urban electricity in Great Britain leads up to the position in 1939 , when of 10.7 million urban dwellings, $\mathbf{7 . 9}$ million were supplied with electricity; among 2.25 million rural dwellings, $1 \cdot 1$ million received a supply, together with at least 35,000 farms. For the completion of rural electrification financial aid will be required for connecting consumers remote from transmission lines, preferably granted for schemes embracing districts as a whole. Wayleave procedure should be simplified and the use of under-eave construction facilitated. Agreement by undertakings on a standard length of underground service cable, laid free, is recommended. A free overhead service line to a total cost not exceeding that of installing the agreed length of underground service cable is suggested. Simplified and less expensive constructions for high-voltage spur lines are proposed, and agreed standards are recommended. Expenditure on such overhead lines must usually be justified by adequate revenue, unless the consumer contributes to first cost or a subsidy is available. Legislation is recommended to bring English law into conformity with Scottish law, which allows a tenant to secure compensation from the landlord for the cost of any wiring installation put in by the tenant. Low-interest loans for wiring, etc., or hire-purchase terms for a ten-year period are advocated.

A report issued in 1930 of a committee set up by the Electricity Commissioners gave a comprehensive picture of the situation at that time and remains largely applicable. The time is appropriate for securing uniformity of tariff forms, and recommendations are made to this end. The merits of the twopart tariff are discussed and recommendations for its wide extension are made. Consumers are classified into the groups domestic, farm, industrial and commercial, and recommendations are made for the equitable assessment of the fixed or primary charge component of the tariffs appropriate to each group. The Electricity Commissioners, it is suggested, should be authorized to permit any undertaking to offer a two-part tariff only, with no alternative flat-rate, subject to certain safeguards to the consumer. Descriptions are given, and the advantages are discussed, of two-part variable-block tariffs, for the above groups, and examples of the working of each are quoted.

Basic changes in the Regulations for the Electrical Equipment of Buildings of the Institution are proposed, leading to their division into Basic Safety Regulations (accompanied by a Code of Practical Interpretation) and supported by Codes of Good Practice to be prepared by the independent Codes of
Practice Committee, set up under the ægis of the Ministry of Works. It is recommended that this very important matter be given early consideration.

No full assessment of the matter of legislative control of the electrical equipment of buildings has been attempted, but an appraisement of the technical aspects of the available evidence does not support a need for the compulsory registration of contractors and operatives or for the exactment at present of compulsory wiring regulations. If necessary, the proposed Basic Safety Regulations could later be given the force of law. Extension of inspection of installations by supply undertakings, more general observance of the wiring regulations, wider use of the voluntary system of registration of installation contractors, insistence on the use of non-kinkable cords for portable apparatus, and the manufacture of accessories and apparatus to extended and specific British standard specifications are recommended.

\section{OPHTHALMOLOGY IN GREAT BRITAIN}

$T$

WE work of the modern ophthalmologist and the tasks he has to face in the future are the subjects of two articles in the British Medical Bulletin (1, No. $9 ; 1913)$. These articles inaugurate a series of outlines of special aspects of British medicine which that journal will publish at irregular intervals in the future.

Discussing the future work of the ophthalmologist, Prof. Arnold Sorsby gives most of his space to blindness, adopting the criterion that blindness means being "so blind as torbe unable to perform any work for which eyesight is essential". He finds that there are at least 100,000 blind people among the population of about 40 million in England and Wales, which is a rate of 2.5 per thousand. It is likely that even now all the blind are not registered by a medical examiner for the benefits obtainable under the Blind Persons Act of 1920 .

In 1910 it was estimated from the census returns of various countries that there were about 3 million totally blind people in the world, but, on the basis of the rate for England and Wales, the world figure would be 5 million. Blindness is, however, much more frequent in India, China and the Middle East than it is in Britain. China alone probably has 4-5 million blind people and India may have almost as many. Prof. Sorsby suggests that there are probably 15 million blind people in the world, and that many millions more have grossly defective sight. Apart from the immediate exciting causes of blindness, the great determining causes are ignorance and poor social and medical services.

The prevention of blindness-surely one of the major tasks of the future-is considered under five hoadings. Among the infective processes causing blindness, ophthalmia neonatorum of the newborn is no longer significant, nor is smallpox now a serious cause of eye disease. Trachoma and the acute ophthalmias of the tropics are not yet controlled. Trachoma probably affects about 15 per cent of the world's population, and its cause is not understood. Possibly a remedy may be found among the sulphonamides. The control of tuberculosis has helped greatly to diminish phlyctenular ophthalmia, the prevalent ophthalmia of childhood, due to tuberculous sensitiza. tion. Advances in public health and hygiene have 
also helped the tasks of the ophthalmologist. But the lack of any specific treatment for tuberculosis makes it difficult to control tuberculous allergy of the eye. Until we find an antisyphilitic agent which will reach and act on the brain and the eye, treatment of ocular syphilis will be unsatisfactory.

Among genetic affections of the eye, malformations and hereditary anomalies cause the blindness of some 50 per cent of blind children. Geneticists should find interesting material in the study of glioma retince, a disease which behaves as an irregular dominant in some families. We need to know why it does not behave as a dominant in those transmitters of it who do not suffer from it.

Among nutritional and metabolic disorders, xerophthalmia is a major problem in China and India. Work is needed on the correlation of nutrition with ocular health and we need better methods of studying the physiology of the eye, so that problems which, like diabetic retinitis, are related to faulty metabolism of the body as a whole, may be tackled on a proper basis. Such methods would also help the study of cataract and glaucoma, which are, according to English and North American statistics, responsible for 25-40 per cent of blindness.

Finally, in children and young adults, injuries are important. War is the greatest single cause of blindness, and it poses its own special problems-the extraction, for example, of non-magnetic fragments from the interior of the eye, such fragments being, in the present War, largely non-magnetic, while those encountered during the War of 1914-18 were not.

In a section on ocular hygiene Prof. Sorsby echoes the opinions of the leaders of modern medical thought when he reminds us that nowadays we tend to take 'optical aids' as a matter of course, and to forget the environmental conditions of those who have to use them. It is good to learn that England may have a national eye service for all, an important part of which will be the research facilities which are essential to its progress. The British Medical Bulletin points out that the Oxford University Ophthalmic Research Endowment Committee is appealing for funds for the endowment of the newly established Department of Ophthalmology at Oxford after the War. Reference was made to this project in NaTuRE of September 18, 1942, p. 323.

In another special article in this issue of the British Medical Bulletin, R. R. James gives an outline of the history of English ophthalmology since its beginnings in the days of the Roman occupation. After the Romans left, the Anglo-Saxons and Normans did little to improve ophthalmic practice, but in the thirteenth century Roger Bacon and John of Peckham initiated the use by old people of lenses for reading, and the science of optics began. Early in the seventeenth century the itinerant oculist Richard Banister of Stamford directed attention to hardness of the eyeball as a cardinal sign of glaucoma, a discovery which was forgotten for 150 years. Banister seems to have been an honest and remarkable member of an itinerant fraternity whose practices should make entertaining reading. Mr. James describes the eighteenth century as the age of ophthalmic quackery, but during it modern ophthalmology was founded by Cheselden, Sharp, Warner and others. In 1805 the Moorfields Eye Hospital, now the Royal London Ophthalmic Hospital, was founded. Exeter established an eye hospital in 1808 and Manchester in 1814. The subsequent landmarks in ophthalmic history given by Mr. James indicate that, when Sir William Bowman, who gave his name to Bowman's membrane, abandoned general surgery to become the first ophthalmic specialist, he began that specialist service which to-day must face so many urgent tasks.

G. LAPAGE.

\section{THIOUREA AS PROTECTIVE AGENT FOR VITAMIN C}

FOOD products rich in ascorbic acid, such as those made from citrus and other fruits, should be processed under conditions in which the vitamin is not destroyed. Ascorbic acid loses its antiscorbutic action when the cyclic structure of the molecule is changed by the opening up of the lactone ring. In alkaline solution this takes place spontaneously with formation of diketogulonic acid, which afterwards breaks down to threonic and oxalic acids from which the vitamin cannot be recovered by simple reduction. This does not readily happen in acid solution, and the vitamin may be oxidized to the dehydro form and quantitatively recovered by the use of the appropriate reducing agents.

Oxidation of the vitamin can occur in the absence of molecular oxygen provided the solution is activated by (1) ultra-violet light, (2) copper, (3) pyridine nucleotides, or (4) enzymes of the type of ascorbic acid oxidase. The possible significance of copper contamination has been recognized in an order by the Ministry of Food by which manufacturers of fruit concentrates containing vitamin $\mathrm{C}$ are required to satisfy the Ministry that their process plants do not come in contact with fruit juices.

It may be sufficient for industrial purposes to ensure that the boiling pans are not lined with copper, the effect of copper parts of the cold sections of the plant being disregarded. Contamination by ionic copper is likely to be much more troublesome, since the metal may be introduced in the water and carried by the fruit, which is often copper-sprayed. Substances capable of protecting the vitamin from destruction following oxidation are (l) substances which stabilize the vitamin in its oxidized (dehydro) or its reduced forms, since either are of equal value in nutrition; (2) reducing agents capable of maintaining the vitamin in the stable or reduced form; (3) buffers which keep the solvent from becoming alkaline; and (4) substances which act as anticatalysts either by depressing the ionization of copper present in the solution or by combining with ascorbic oxidases.

Reduced ascorbic acid is stable in tissue fluids and in natural and processed food materials containing appreciable quantities of copper. This stability is due to the presence of substances such as glutathione which form copper compounds of a low degree of ionization. E. Kawereau and W. R. Fearon ( $S c i$. Proc. Roy. Dublin Soc., 23, 171 ; 1944) have recently investigated a large number of substances which might protect ascorbic acid from oxidation in the presence of copper. Of all the simple solutes tested, thiourea was outstanding in its protective power. It appears to be of very low toxicity and is excreted unchanged by the kidney after administration to human subjects. It displays none of the pharmacological effects possessed by some of the substituted thioureas. The authors, however, consider that more work is required on the effects of long-continued 